\title{
Vaccination with Legionella pneumophila Membranes Induces Cell-mediated and Protective Immunity in a Guinea Pig Model of Legionnaires' Disease
}

\author{
Protective Immunity Independent of the Major Secretory Protein of Legionella pneumophila
}

\author{
Steven J. Blander and Marcus A. Horwitz \\ Division of Infectious Diseases, Department of Medicine, UCLA School of Medicine, Center for the Health Sciences, \\ Los Angeles, California 90024
}

\begin{abstract}
We have examined the capacity of Legionella pneumophila membranes to induce cell-mediated immune responses and protective immunity in a guinea pig model of Legionnaires' disease. Guinea pigs immunized by aerosol with $L$. pneumophila membranes developed strong cell-mediated immune responses to $L$. pneumophila membranes as demonstrated by cutaneous delayed-type hypersensitivity and in vitro splenic lymphocyte proliferation. Guinea pigs immunized by aerosol or by subcutaneous inoculation with $L$. pneumophila membranes developed strong protective immunity against lethal aerosol challenge with $L$. pneumophila. Overall, in six independent experiments, 39 of $49(80 \%)$ guinea pigs immunized with L. pneumophila membranes survived challenge compared with 2 of $40(5 \%)$ sham-immunized controls $\left(P=2 \times 10^{-13}\right)$. In contrast, guinea pigs immunized by aerosol with formalin-killed $L$. pneumophila did not develop either a strong cell-mediated immune response to $L$. pneumophila antigens or protective immunity to lethal aerosol challenge.

The capacity of $L$. pneumophila membranes to induce protective immunity was independent of the major secretory protein of $L$. pneumophila, which we previously demonstrated is an immunoprotective molecule. Purified $L$. pneumophila membranes did not contain detectable major secretory protein (MSP) on immunoblots; immunization of guinea pigs with $\boldsymbol{L}$. pneumophila membranes did not induce anti-MSP antibody; and guinea pigs developed comparable protective immunity after immunization with membranes from either an $L$. pneumophila strain that secretes the major secretory protein or an isogenic mutant that does not.
\end{abstract}

This study demonstrates that $(a)$ immunization with $L$. pneumophila membranes but not formalin-killed $L$. pneumophila induces strong cell-mediated immune responses and protective immunity, (b) L. pneumophila membranes contain immunoprotective molecules distinct from the major secretory protein of $L$. pneumophila, and (c) L. pneumophila membranes

This paper was presented in part at the 1990 National Meeting of the Association of American Physicians, the American Society for Clinical Investigation, and the American Federation for Clinical Research, 4-7 May 1990, Washington, DC.

Address reprint requests to Dr. Horwitz, Division of Infectious Diseases, Department of Medicine, Center for the Health Sciences, 10833 Le Conte Avenue, Los Angeles, CA 90024-1736. 1990.

Received for publication 13 July 1990 and in revised form 8 October

J. Clin. Invest.

(C) The American Society for Clinical Investigation, Inc.

0021-9738/91/03/1054/06 \$2.00

Volume 87, March 1991, 1054-1059 have potential as a vaccine against Legionnaires' disease. ( $J$. Clin. Invest. 1991. 87:1054-1059.). Key words: $L$. pneumophila $\bullet$ membrane $\cdot$ vaccine $\bullet$ protective immunity $\bullet$ Legionnaires' disease $\bullet$ cell-mediated immunity

\section{Introduction}

Legionella pneumophila is a facultative intracellular bacterial pathogen that causes $80-85 \%$ of the cases of Legionnaires' disease, a serious and often fatal form of pneumonia $(1,2)$. Patients with Legionnaires' disease develop both humoral and cell-mediated immune responses to L. pneumophila (3-5). Cell-mediated immunity appears to play a vital role in host defense. Activated human monocytes and alveolar macrophages inhibit the intracellular multiplication of $L$. pneumophila (5-9). Humoral immunity appears to play a lesser role in host defense $(3,4)$.

The guinea pig is an excellent animal model for the study of Legionnaires' disease. When exposed to aerosols containing $L$. pneumophila, guinea pigs develop a pneumonic illness that is clinically and pathologically similar to Legionnaires' disease in humans (10-14).

Previous studies from this laboratory have demonstrated that guinea pigs immunized with a sublethal aerosolized dose of wild-type L. pneumophila, or with an aerosolized dose of an avirulent mutant $L$. pneumophila develop humoral and cellmediated immune responses to wild-type $L$. pneumophila antigens, and protective immunity against lethal aerosol challenge with wild-type $L$. pneumophila $(15,16)$. To identify immunoprotective antigens of $L$. pneumophila, we have focused our attention on native antigens recognized by the lymphocytes of such immune guinea pigs. Previous studies have identified two such antigenic preparations: the major secretory protein (MSP) ${ }^{1}$ of L. pneumophila and L. pneumophila membranes $(16,17)$.

A previous study from this laboratory explored the capacity of MSP to induce immune responses in the guinea pig. This study demonstrated that MSP is an immunoprotective molecule (17). This study showed that guinea pigs immunized subcutaneously with MSP develop humoral and cell-mediated immune responses to MSP, and protective immunity against lethal aerosol challenge with $L$. pneumophila.

Although MSP is an immunoprotective molecule, it is not a virulence determinant in the guinea pig model of Legionnaires' disease (18). We have shown that an isogenic MSP-negative strain of $L$. pneumophila is as virulent for guinea pigs as the parental MSP-positive strain (18). Moreover, we have shown

1. Abbreviations used in this paper: CYEA, charcoal yeast extract agar; EYB, egg yolk buffer; FKLP, formalin-killed wild-type Legionella pneumophila; MSP, major secretory protein; SI, stimulation index. 
that naturally occurring species of Legionella that do not produce MSP are nevertheless virulent (19). That guinea pigs immunized with a sublethal dose of such species develop protective immunity against the vaccine strain has suggested the existence of other immunoprotective molecules of Legionella (19).

In the present study, we have examined the capacity of $L$. pneumophila membranes to induce immune responses in the guinea pig. First, we shall demonstrate that immunization of guinea pigs with $L$. pneumophila membranes induces strong cell-mediated immune responses to L. pneumophila membrane antigens and protective immunity against lethal aerosol challenge with $L$. pneumophila. Secondly, we shall demonstrate that $L$. pneumophila membranes induce protective immunity independent of MSP, since ( $a$ ) the membranes do not contain MSP, $(b)$ immunization of guinea pigs with membranes does not induce an immune response against MSP, and (c) immunization of guinea pigs with membranes of MSPnegative $L$. pneumophila induces protective immunity comparable to that of immunization with membranes of MSP-positive L. pneumophila. Finally, we shall show that immunization of guinea pigs with formalin-killed $L$. pneumophila, in contrast to $L$. pneumophila membranes, does not induce strong cellmediated immune responses or protective immunity against lethal aerosol challenge with L. pneumophila. This study demonstrates that $L$. pneumophila membranes contain immunoprotective molecules distinct from MSP and that these membranes have potential as a vaccine against Legionnaires' disease.

\section{Methods}

Media. Each liter of albumin yeast extract broth was prepared with $10 \mathrm{~g}$ of Aces (Sigma Chemical Co., St. Louis, MO), $5 \mathrm{~g}$ of bovine serum albumin fraction $\mathrm{V}$ (Sigma Chemical Co.), $10 \mathrm{~g}$ of yeast extract (Difco Laboratories, Detroit, MI), $0.4 \mathrm{~g}$ of L-cysteine $\mathrm{HCl}$ (Fisher Scientific Co., Fairlawn, NJ), and $0.25 \mathrm{~g}$ of ferric pyrophosphate (Sigma Chemical Co.) adjusted to $\mathrm{pH} 6.9$ with $10 \mathrm{~N} \mathrm{KOH}$, and filter-sterilized.

RPMI 1640 with L-glutamine (Gibco Laboratories, Grand Island, $\mathrm{NY})$ was mixed with penicillin $(100 \mathrm{U} / \mathrm{ml})$ and streptomycin $(100 \mu \mathrm{g} /$ $\mathrm{ml}$ ) (Gibco Laboratories). Egg yolk buffer (EYB) with or without $1 \%$ bovine serum albumin (BSA, Miles Laboratories Inc., Naperville, IL) was prepared as previously described (1).

Agar. Modified charcoal yeast extract agar (CYEA) was prepared as described (1). Modified CYEA without cysteine and tryptic soy agar with $5 \%$ sheep blood were used to assay for contaminating bacteria.

Bacteria. L. pneumophila, Philadelphia 1 strain (serogroup 1), was grown in embryonated hens' eggs, harvested, tested for viability, tested for the presence of contaminating bacteria, passed one time only on CYEA, washed with EYB; flash frozen in aliquots of $10^{\text {" }}$ colony-forming units $(\mathrm{CFU}) / \mathrm{ml}$, and stored at $-70^{\circ} \mathrm{C}(1)$. Before use in the aerosol inoculation system, a stock preparation of bacteria was diluted in EYB to the desired concentration.

An isogenic pair of $L$. pneumophila, Philadelphia 1 strain, one of which is MSP-positive (MSP+) (LS2029) and one of which is MSPnegative (MSP-) (LS2 102) (18), and an avirulent mutant $L$. pneumophila, Philadelphia 1 strain (16), were grown on CYEA, washed with EYB, flash frozen in aliquots of $10^{11} \mathrm{CFU} / \mathrm{ml}$, stored at $-70^{\circ} \mathrm{C}$, and tested for the presence of contaminating bacteria as previously described (1). The MSP- strain was constructed by Howard Shuman and Lisa Szeto (Columbia University) by inserting transposon $\mathrm{Tn} 9$ in the structural gene for MSP, $m s p A$, in an Escherichia coli host strain and subsequently transferring the insertion to the genome of the parental MSP+ strain (LS2029), as previously described (18).

Membranes. Membranes were prepared from wild-type L. pneumophila, MSP- L. pneumophila, and MSP+ L. pneumophila as previously described with the following modifications (20). Briefly, bacteria were grown in AYE broth to an optical density (OD) of 1.0 at 540 $\mathrm{nm}$, harvested by centrifugation at $11,000 \mathrm{~g}$ for $10 \mathrm{~min}$ at $4^{\circ} \mathrm{C}$, washed in $50 \mathrm{mM}$ Tris, $\mathrm{pH} 7.5$, and then resuspended in $9.5 \mathrm{ml}$ of $0.2 \mathrm{M}$ Tris, $0.5 \mathrm{M}$ sucrose, $\mathrm{pH}$ 8.0. The bacteria were first incubated with $100 \mu \mathrm{l}$ of 0.1 M EDTA, pH 8.0, subsequently incubated with lysozyme (Sigma Chemical Co.) to a final concentration of $0.1 \mathrm{mg} / \mathrm{ml}$, and then diluted in $10 \mathrm{ml}$ of double-distilled water. After $20 \mathrm{~min}$, the suspension was centrifuged at $5,000 \mathrm{~g}$ for $10 \mathrm{~min}$ at $4^{\circ} \mathrm{C}$. The pellet was resuspended in $400 \mu \mathrm{l}$ of $50 \mathrm{mM}$ Tris, $20 \mathrm{mM} \mathrm{MgSO}$, pH 7.4, added to $100 \mathrm{ml}$ of 5

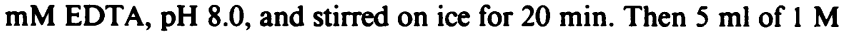
Tris, pH 7.4, $2 \mathrm{ml}$ of $1 \mathrm{M} \mathrm{MgSO}_{4}$, and $200 \mu \mathrm{l}$ of $1 \mathrm{mg} / \mathrm{ml} \mathrm{DNase} \mathrm{I}$ (Sigma Chemical Co.) were added. After $10 \mathrm{~min}$ on ice and $10 \mathrm{~min}$ at room temperature, the suspension was centrifuged at $5,000 \mathrm{~g}$ for $5 \mathrm{~min}$ at $4^{\circ} \mathrm{C}$, and the pellet discarded. The bacterial membranes in the suspension were collected by centrifugation at $178,000 \mathrm{~g}$ for $110 \mathrm{~min}$ at $4^{\circ} \mathrm{C}$ and enumerated in a Petroff-Hausser chamber.

Formalin-killed L. pneumophila. Formalin-killed wild-type $L$. pneumophila (FKLP) was prepared as previously described (5).

Animals. Male Hartley strain guinea pigs weighing $250-300 \mathrm{~g}$ (Simonson Laboratories, Gilroy, CA), were cared for as previously described (16). They were observed in the vivarium for $1 \mathrm{wk}$ before challenge with $L$. pneumophila to ensure that they were healthy. No illnesses or deaths occurred in the guinea pigs before challenge.

Immunization of guinea pigs by aerosol. Guinea pigs were immunized by exposure to aerosols containing bacteria or membranes in the same lucite aerosol chamber described in detail in a previous study (15). Guinea pigs were immunized with an aerosol generated from a 10-ml suspension containing one of the following: $2.5 \times 10^{9}$ wild-type L. pneumophila membranes $/ \mathrm{ml}, 5.0 \times 10^{9} \mathrm{FKLP} / \mathrm{ml}, 5.0 \times 10^{9}$ avirulent mutant $L$. pneumophila/ml, or EYB (sham-immunized controls). Animals were immunized four times at 3-wk intervals with $L$. pneumophila membranes; two or four times at 3-wk intervals with FKLP; and one time with the avirulent mutant $L$. pneumophila.

Immunization of guinea pigs by subcutaneous inoculation. Wildtype, MSP-, and MSP+ L. pneumophila membranes were diluted in EYB to a concentration of $5 \times 10^{8}$ membranes $/ \mathrm{ml}$. The injection sites of the guinea pigs were washed with $70 \%$ ethanol, and the animals were then injected subcutaneously with $200 \mu \mathrm{l}\left(10^{8}\right.$ membranes) of one of the membrane preparations. Each animal was immunized twice at a 3-wk interval. Control guinea pigs were sham-immunized twice with $200 \mu$ l of EYB.

Cutaneous delayed-type hypersensitivity. Immunized or control (sham-immunized) guinea pigs were shaved over the back and flank and injected intradermally with $100 \mu \mathrm{l}$ of the immunizing antigen (wild-type L. pneumophila membranes or FKLP at a concentration of $10^{8}$ particles $/ \mathrm{ml}$ ), and with $100 \mu \mathrm{l}$ of the diluting buffer (EYB). The diameters of erythema and induration were measured at skin test sites $24 \mathrm{~h}$ after injection.

Lymphocyte proliferation assay. Splenic mononuclear cells from immunized or control (sham-immunized) guinea pigs were obtained and purified, incubated with antigen (wild-type L. pneumophila or FKLP), or control medium in triplicate microtest wells for $2 \mathrm{~d}$, and then tested for their capacity to incorporate ${ }^{3}[\mathrm{H}]$ thymidine as described (15).

Protective immunity. Guinea pigs were challenged 3 wk after immunization with a $100 \%$ lethal dose of wild-type $L$. pneumophila. This dose, which was generated from a 10-ml suspension of wild-type $L$. pneumophila containing $2.5 \times 10^{8} \mathrm{CFU} / \mathrm{ml}$, was the lowest dose that consistently resulted in the death of nonimmunized guinea pigs, as previously described (15). After challenge, animals were held in filtertop cages for $1 \mathrm{wk}$. During this time they were observed for signs of illness, and survival was quantitated. Differences in survival between immunized and control animals were evaluated by the Fisher's Exact Test, two-tailed.

Immunoblot analysis of L. pneumophila membranes for MSP. Wild-type $L$. pneumophila membranes were examined for the presence of MSP by immunoblot analysis $(21,22)$, using the alkaline phosphatase technique for immunostaining (23). Briefly, 1.0, 0.1, and $0.01 \mu \mathrm{g}$ 
of MSP, and $\sim 10^{8}$ particles of wild-type L. pneumophila membranes were subjected to SDS-PAGE and transferred to nitrocellulose (Schleicher \& Schuell Inc., Keene, NH). The nitrocellulose bound membrane proteins were incubated first with a 1:200 dilution of the sera obtained from guinea pigs immunized with $40 \mu \mathrm{g}$ of MSP twice, 3 wk apart, as previously described (reciprocal titer $>2,056$ by ELISA) (17) and then incubated with a 1:1,000 dilution of alkaline phosphatase-conjugated goat anti-guinea pig IgG (whole molecule) (Sigma Chemical Co.). The enzyme substrate solution used for visualization consisted of $500 \mu \mathrm{l}$ of $0.1 \%$ nitroblue tetrazolium (Sigma Chemical Co.), $100 \mu 1$ of $0.5 \%$ 5-bromo-4-chloro-indolyl phosphate (Sigma Chemical Co.) in anhydrous dimethyl formamide (Pierce Chemical Co., Rockford, IL), and $9.5 \mathrm{ml}$ of $0.05 \mathrm{M}$ Tris, $0.03 \mathrm{M} \mathrm{MgCl}_{2}, \mathrm{pH} 10$. Analysis of capacity of $L$. pneumophila membranes to induce antiMSP antibody. Wild-type L. pneumophila membranes were further examined for the presence of MSP by analyzing their capacity to induce anti-MSP antibody. Guinea pigs were immunized subcutaneously with wild-type membranes twice at a 3-wk interval. Their sera were collected 3 wk later and assayed for the presence of anti-MSP antibody by immunoblot analysis. Briefly, 1.0,0.1, and $0.01 \mu \mathrm{g}$ of MSP and $10^{8}$ membranes were subjected to sodium dodecyl sulfate-polyacrylamide gel electrophoresis (SDS-PAGE), transferred to nitrocellulose, incubated first with a 1:200 dilution of the sera obtained from the membrane-immunized guinea pigs, and then incubated with a 1:1,000 dilution of alkaline phosphatase-conjugated goat anti-guinea pig IgG (whole molecule). The enzyme substrate solution described above was used for visualization.

\section{Results}

Guinea pigs immunized with L. pneumophila membranes but not sham-immunized controls develop marked cutaneous delayed-type hypersensitivity to L. pneumophila membrane antigens. To determine whether guinea pigs immunized by aerosol with $L$. pneumophila membranes develop cutaneous delayedtype hypersensitivity to $L$. pneumophila membrane antigens, we injected immunized and control guinea pigs intradermally with $10^{8}$ wild-type $L$. pneumophila membranes 3 wk after immunization, and measured the extent of erythema and induration at skin test sites $24 \mathrm{~h}$ later.

Membrane-immunized guinea pigs exhibited greater areas of erythema and induration at skin test sites than control guinea pigs (Table I, expt. A). The membrane-immunized animals had a mean diameter of erythema 3.0 times and mean diameter of induration 4.1 times that of control animals. These differences achieved significance for erythema $(P<0.05, t$ test, two-tailed), and nearly achieved significance for induration $(P$ $<0.1, t$ test, two-tailed).

Guinea pigs immunized with FKLP do not develop cutaneous delayed-type hypersensitivity to FKLP antigens. To determine whether guinea pigs immunized by aerosol with FKLP develop cutaneous delayed-type hypersensitivity to FKLP antigens, we skin-tested FKLP-immunized and control guinea pigs 3 wk after immunization.

In contrast to membrane-immunized guinea pigs, FKLPimmunized guinea pigs did not exhibit greater areas of erythema and induration than controls at skin test sites (Table I, expt. B). The FKLP-immunized animals had a slightly less mean diameter of erythema ( 0.8 times) than controls and a similar mean diameter of induration (1.0 times).

Guinea pigs immunized with L. pneumophila membranes exhibit marked in vitro splenic lymphocyte proliferation in response to L. pneumophila membrane antigens. To determine whether splenic lymphocytes from guinea pigs immunized by aerosol with $L$. pneumophila membranes proliferate in vitro in
Table I. Guinea Pigs Immunized with L. pneumophila Membranes but Not FKLP Develop Cutaneous Delayed-type Hypersensitivity to L. pneumophila Membrane Antigens

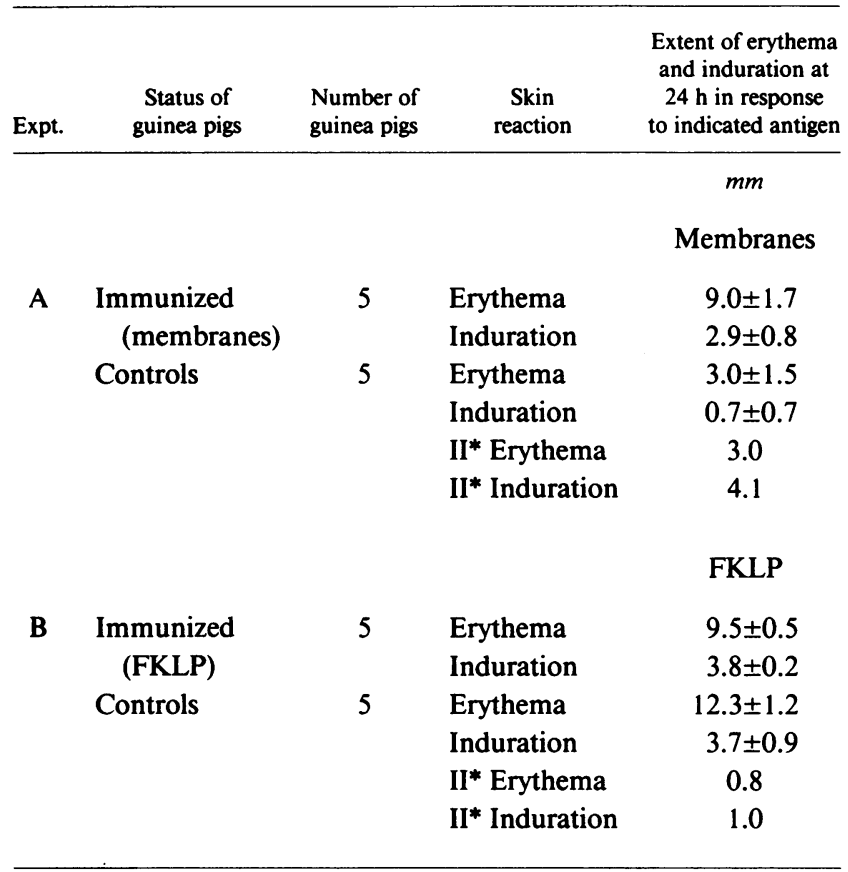

Guinea pigs were immunized with $L$. pneumophila membranes (expt. A) or FKLP (expt. B) or sham-immunized (controls) by aerosol four times, at 3-wk intervals. The animals were skin tested 3-4 wk later with an intradermal injection of $10^{7} \mathrm{~L}$. pneumophila membranes or FKLP, and the extent of erythema and induration was measured 24 $\mathrm{h}$ later. Data are the mean \pm SEM diameter of erythema and induration for each group of animals. Neither immunized nor control animals developed erythema or induration in response to the phosphate buffer in which the antigens were diluted.

* II, inflammation index $=$ [mean skin reactivity $(\mathrm{mm})$ of immunized guinea pigs]/[mean skin reactivity ( $\mathrm{mm}$ ) of control guinea pigs].

response to L. pneumophila membrane antigens, we examined proliferative responses of lymphocytes from immunized and control guinea pigs $3 \mathrm{wk}$ after immunization.

Membrane-immunized guinea pigs exhibited significantly greater splenic lymphocyte proliferation in response to $L$. pneumophila membranes than control guinea pigs (Table II, expt. A). Splenic lymphocytes from membrane-immunized animals had a mean stimulation index (SI) of $50.3 \pm 3.7$ in response to $L$. pneumophila membranes whereas lymphocytes from control animals had a mean SI of $9.0 \pm 5.3(P<0.01, t$ test, two-tailed). Membrane-immunized guinea pigs also exhibited greater splenic lymphocyte proliferation in response to FKLP $(\mathrm{SI}=71.7 \pm 14.5)$ than controls $(\mathrm{SI}=32.6 \pm 21.6)$ but the difference was not statistically significant.

FKLP-immunized animals also exhibited greater splenic lymphocyte proliferation than control animals in response to L. pneumophila membranes or FKLP, but the differences were not statistically significant for either antigen (Table II, expt. B).

Guinea pigs immunized with L. pneumophila membranes by aerosol or subcutaneous inoculation develop protective immunity against lethal aerosol challenge. To determine if guinea pigs immunized with $L$. pneumophila membranes develop protective immunity, we challenged membrane-immunized animals and sham-immunized control animals with a lethal aero- 
Table II. Guinea Pigs Immunized with Wild-type L. pneumophila Membranes Exhibit Marked Splenic Lymphocyte Proliferation in Response to L. pneumophila Membrane Antigens

\begin{tabular}{|c|c|c|c|c|}
\hline \multirow[b]{2}{*}{ Expt. } & \multirow{2}{*}{$\begin{array}{l}\text { Status of } \\
\text { guinea pigs }\end{array}$} & \multirow{2}{*}{$\begin{array}{l}\text { Number of } \\
\text { guinea pigs }\end{array}$} & \multicolumn{2}{|c|}{$\begin{array}{l}\text { SI in response } \\
\text { to indicated antigen }\end{array}$} \\
\hline & & & Membranes & FKLP \\
\hline \multirow[t]{3}{*}{ A } & $\begin{array}{l}\text { Immunized } \\
\text { (Membranes) }\end{array}$ & 2 & $50.3 \pm 3.7$ & $71.7 \pm 14.5$ \\
\hline & Controls & 2 & $9.0 \pm 5.3$ & $32.6 \pm 21.6$ \\
\hline & $P^{\ddagger}$ & & $<0.01$ & $<0.4$ \\
\hline \multirow[t]{3}{*}{ B } & $\begin{array}{l}\text { Immunized } \\
\text { (FKLP) }\end{array}$ & 2 & $12.9 \pm 2.9$ & $18.0 \pm 3.6$ \\
\hline & Controls & 2 & $6.6 \pm 0.7$ & $6.6 \pm 1.5$ \\
\hline & $P^{\ddagger}$ & & $<0.2$ & $<0.1$ \\
\hline
\end{tabular}

Guinea pigs were sham-immunized or immunized with wild-type $L$. pneumophila membranes (expt. A) or FKLP by aerosol four times, at 3-wk intervals. 3-4 wk later, the guinea pigs were killed, and splenic lymphocytes were assayed for their capacity to proliferate in response to wild-type $L$. pneumophila membranes and FKLP at the concentration indicated. Data are the mean \pm SEM of the SI for each group of animals. ${ }^{*} \mathrm{SI}=\left(\right.$ mean $\left[{ }^{3} \mathrm{H}\right]$ thymidine incorporation [cpm] of lymphocytes incubated with antigen)/(mean $\left[{ }^{3} \mathrm{H}\right]$ thymidine incorporation [cpm] of lymphocytes incubated without antigen). ${ }^{\ddagger} P$ value for difference between SI of immunized and control guinea pigs by $t$ test, two-tailed.

sol dose of wild-type L. pneumophila and quantitated survival (Table III). In two independent experiments, guinea pigs immunized by aerosol with $L$. pneumophila membranes demonstrated significantly greater survival than control animals (Table III, expts. A and B). Overall, 11 of 12 (92\%) animals immunized with membranes by aerosol survived, compared to 1 of
$12(8 \%)$ control animals $\left(P=5 \times 10^{-5}\right.$, Fisher's Exact Text, two-tailed). In three independent experiments, guinea pigs immunized by subcutaneous inoculation with $L$. pneumophila membranes demonstrated significantly greater survival than control animals (Table III, expts. C, D, and E). Overall, 11 of $14(79 \%)$ animals immunized with membranes subcutaneously survived, compared to 1 of $16(6 \%)$ control animals $(P=9$ $\times 10^{-5}$, Fisher's Exact Text, two-tailed).

Immunized animals first exhibited signs of illness including decreased activity, decreased feeding, and respiratory distress, $1 \mathrm{~d}$ after challenge, but they then recovered. Sham-immunized (control) animals first exhibited these signs of illness $2 \mathrm{~d}$ after challenge, but they did not recover. All animals surviving by 7 $\mathrm{d}$ after challenge recovered fully from earlier signs of disease.

The capacity of L. pneumophila membranes to induce protective immunity is independent of MSP. As noted in the introduction, $L$. pneumophila MSP is a potent protective immunogen. To examine the possibility that MSP associated with $L$. pneumophila membranes was responsible for the immunoprotective capacity of the membranes, we examined L. pneumophila membranes for MSP (Fig. 1).

We first prepared immunoblots of $L$. pneumophila membranes and probed the blots for the presence of MSP using high-titer anti-MSP antiserum. Whereas anti-MSP antiserum detected as little as $0.01 \mu \mathrm{g}$ MSP in control lanes of the immunoblots (readily visualized on the original of Fig. 1, left, lane C), this antiserum detected no MSP in any preparation of $L$. pneumophila membranes (Fig. 1, left, lane $D$ ).

We also investigated whether immunization of guinea pigs with $L$. pneumophila membranes induced anti-MSP antibody. We immunized guinea pigs with $L$. pneumophila membranes, collected their sera, and assayed the sera for anti-MSP antibody by immunoblot analysis. Whereas antisera readily reacted with L. pneumophila membranes in the control lane of immunoblots (Fig. 1, right, lane $D$ ), the antisera did not react with even

Table III. Guinea Pigs Immunized with L. pneumophila Membranes Develop Protective Immunity against Lethal Aerosol Challenge with Wild-type L. pneumophila

\begin{tabular}{|c|c|c|c|c|c|}
\hline Expt. & Status of guinea pigs & $\begin{array}{l}\text { Number } \\
\text { of expts. }\end{array}$ & $\begin{array}{c}\text { Number of guinea pigs surviving } \\
\text { per number challenged }\end{array}$ & $\begin{array}{l}\text { Percent } \\
\text { survival }\end{array}$ & $P^{*}$ \\
\hline \multirow[t]{2}{*}{ A, B } & $\begin{array}{l}\text { Immunized } \\
\text { (membranes by aerosol) }\end{array}$ & 2 & $11 / 12$ & 92 & $5 \times 10^{-5}$ \\
\hline & Controls & & $1 / 12$ & 8 & \\
\hline \multirow[t]{2}{*}{ C, D, E } & $\begin{array}{l}\text { Immunized } \\
\text { (membranes SQ) }\end{array}$ & 3 & $11 / 14$ & 79 & $9 \times 10^{-5}$ \\
\hline & Controls & & $1 / 16$ & 6 & \\
\hline \multirow[t]{3}{*}{ F, G } & $\begin{array}{l}\text { Immunized } \\
\quad(\text { MSP - membranes SQ) }\end{array}$ & 2 & $8 / 11$ & 73 & $3 \times 10^{-4}$ \\
\hline & $\begin{array}{l}\text { Immunized } \\
\quad(\mathrm{MSP}+\text { membranes SQ) }\end{array}$ & & $9 / 12$ & 75 & $3 \times 10^{-4}$ \\
\hline & Controls & & $0 / 12$ & 0 & \\
\hline \multirow[t]{2}{*}{ Total } & $\begin{array}{l}\text { Immunized } \\
\text { (membranes) }\end{array}$ & 7 & $39 / 49$ & 80 & $2 \times 10^{-13}$ \\
\hline & Controls & & $2 / 40$ & 5 & \\
\hline
\end{tabular}

In seven independent experiments (A-G), guinea pigs were immunized by aerosol with L. pneumophila membranes (A, B), immunized subcutaneously (SQ) with L. pneumophila membranes (C, D, E), immunized subcutaneously with MSP- or MSP+L. pneumophila membranes (F, G), or sham-immunized (controls). $3 \mathrm{wk}$ after immunization, the animals were challenged with a lethal aerosol dose of wild-type L. pneumophila, and survival was quantitated. Data for experiments of each type are combined. ${ }^{*} P$ value for difference in survival between immunized and control guinea pigs by Fisher's Exact Test, two-tailed. 


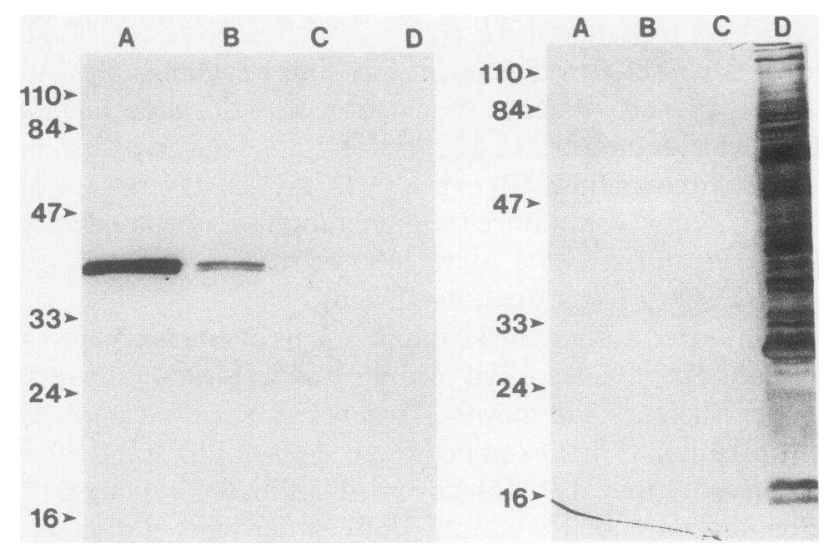

Figure 1. L. pneumophila membranes do not contain MSP or induce antibody to MSP in guinea pigs. MSP and wild-type L. pneumophila membranes were subjected to SDS-PAGE, blotted to nitrocellulose, and probed with either guinea pig anti-MSP antiserum $(l e f t)$ or guinea pig anti-L. pneumophila membrane antiserum (right). $(A) 1.0 \mu \mathrm{g}$ of MSP; (B) $0.1 \mu \mathrm{g}$ of MSP; $(C) 0.01 \mu \mathrm{g}$ of MSP; $(D) 10^{8}$ wild-type $L$. pneumophila membranes. Molecular mass standards are in kilodaltons.

as much as $1 \mu \mathrm{g}$ of MSP (Fig. 1, right, lane $A$ ). These studies demonstrated that $L$. pneumophila membranes do not contain MSP.

To confirm that the capacity of $L$. pneumophila membranes to induce protective immunity is independent of MSP, we immunized guinea pigs with membranes prepared from an MSP - strain of L. pneumophila and examined if the animals developed protective immunity. We immunized guinea pigs with MSP- L. pneumophila membranes or with MSP+ $L$. pneumophila membranes (positive control), and challenged these animals and sham-immunized control animals with a lethal aerosol dose of wild-type L. pneumophila. In two independent experiments, guinea pigs immunized subcutaneously with MSP - L. pneumophila membranes demonstrated significantly greater survival than controls (Table III, expts. F and G). Overall, 8 of $11(73 \%)$ animals immunized with MSP- $L$. pneumophila membranes survived lethal aerosol challenge compared to 0 of $12(0 \%)$ sham-immunized control animals ( $P$ $=3 \times 10^{-4}$, Fisher's Exact Test, two-tailed). As in the case of guinea pigs immunized with wild-type $L$. pneumophila membranes, guinea pigs immunized with MSP+ L. pneumophila membranes exhibited significantly greater survival than controls to lethal aerosol challenge (Table III, expts. F and G). Overall, 9 of $12(75 \%)$ animals immunized with MSP $+L$. pneumophila membranes survived challenge $\left(P=3 \times 10^{-4}\right.$ compared to controls, Fisher's Exact Test, two-tailed).

Guinea pigs immunized with FKLP do not develop protective immunity against lethal aerosol challenge. To determine if guinea pigs immunized with FKLP develop protective immunity, we immunized guinea pigs with FKLP or with an avirulent mutant L. pneumophila (positive control) by aerosol, and challenged these animals and sham-immunized control animals with a lethal aerosol dose of wild-type $L$. pneumophila (Table IV). In two independent experiments, guinea pigs immunized with FKLP exhibited no protective immunity. None $(0 \%)$ of the 11 FKLP-immunized animals and none $(0 \%)$ of the 12 sham-immunized control animals survived lethal aerosol challenge ( $P=1.0$, Fisher's Exact Test, two-tailed). In contrast, 8 of $11(73 \%)$ animals immunized with the avirulent mutant $L$.
Table IV. Guinea Pigs Immunized with FKLP Do Not Develop Protective Immunity against Lethal Aerosol Challenge with Wild-Type L. pneumophila

\begin{tabular}{|c|c|c|c|c|}
\hline $\begin{array}{c}\text { Status of } \\
\text { guinea pigs }\end{array}$ & $\begin{array}{l}\text { Number } \\
\text { of expts. }\end{array}$ & $\begin{array}{l}\text { Number of } \\
\text { guinea pigs } \\
\text { surviving } \\
\text { per number } \\
\text { challenged }\end{array}$ & $\begin{array}{l}\text { Percent } \\
\text { survival }\end{array}$ & $P^{*}$ \\
\hline \multicolumn{5}{|l|}{ Immunized } \\
\hline (FKLP) & 2 & $0 / 11$ & 0 & 1.0 \\
\hline \multicolumn{5}{|l|}{$\begin{array}{l}\text { Immunized } \\
\text { (mutant }\end{array}$} \\
\hline L. pneumophila) & 2 & $8 / 11$ & 73 & $3 \times 10^{-4}$ \\
\hline Controls & 2 & $0 / 12$ & 0 & \\
\hline
\end{tabular}

In two independent experiments, guinea pigs were immunized with FKLP or sham-immunized (controls) by aerosol four times in the first experiment or twice in the second experiment, at 3-wk intervals. As a positive control, an additional group of guinea pigs was immunized with an avirulent mutant $L$. pneumophila by aerosol once in each experiment. $3 \mathrm{wk}$ later, the animals were challenged with a lethal aerosol dose of wild-type L. pneumophila, and survival was quantitated. Data for the two experiments are combined.

* $P$ value for difference in survival between immunized and control guinea pigs by Fisher's Exact Test, two-tailed.

pneumophila survived challenge ( $P=3 \times 10^{-4}$ compared to sham-immunized controls, Fisher's Exact Test, two-tailed).

\section{Discussion}

This paper demonstrates that immunization of guinea pigs with $L$. pneumophila membranes induces cell-mediated and protective immunity in the guinea pig model of Legionnaires' disease. Immunization with membranes either by aerosol or subcutaneous inoculation induces protective immunity.

The capacity of $L$. pneumophila to induce protective immunity is independent of MSP, which was previously shown to be a potent protective immunogen (17). Several pieces of evidence support this conclusion. First, L. pneumophila membranes do not contain detectable MSP; by immunoblot analysis, $10^{8}$ membranes (an immunizing dose) contained $<0.01 \mu \mathrm{g}$ of MSP, the lowest amount assayed. Even this amount of MSP would be two orders of magnitude less than that required to induce protective immunity in the guinea pig model of Legionnaires' disease. In a previous study, two immunizations with $z 2.5 \mu \mathrm{g}$ of MSP were required to induce protective immunity against lethal aerosol challenge, while two immunizations with $0.6 \mu \mathrm{g}$ of MSP did not induce significant protective immunity. Thus, any undetected MSP associated with membranes would be present in an amount below the threshold required to induce protective immunity. Secondly, subcutaneous immunization of guinea pigs with $L$. pneumophila membranes does not induce anti-MSP antibody, which is induced by subcutaneous immunization with MSP. Thus, if $L$. pneumophila membranes contained any MSP, it was in an amount insufficient to induce a humoral immune response. Third, immunization of guinea pigs with membranes derived from an isogenic MSP- strain of L. pneumophila induces strong protective immunity against lethal aerosol challenge. These results indicate that other antigens in $L$. pneumophila membranes are capable of inducing protective immunity. 
L. pneumophila membranes induce cell-mediated and protective immunity in the absence of an exogenous adjuvant. This suggests that $L$. pneumophila membranes have intrinsic adjuvanticity. This is consistent with a previous finding that killed $L$. pneumophila had adjuvant activity comparable to that of killed mycobacteria in promoting humoral immune responses (24). Our study also suggests that $L$. pneumophila membranes have adjuvant activity for cell-mediated as well as humoral immune responses.

In contrast to L. pneumophila membranes, FKLP did not induce a strong cell-mediated immune response or induce protective immunity. This suggests that formalin treatment of $L$. pneumophila modifies its antigenicity in some critical way. Several vaccines against other pathogens are composed of formalin-treated organisms. Our study suggests that such treatment would not be advantageous against $L$. pneumophila and perhaps other organisms where cell-mediated immune responses are important.

In previous studies, we have shown that two other vaccine preparations induce protective immunity against lethal aerosol challenge with $L$. pneumophila: an avirulent mutant $L$. pneumophila and MSP $(16,17)$. L. pneumophila membranes theoretically possess some advantages over each of these vaccine preparations. First, L. pneumophila membranes, in contrast to the avirulent mutant, are not live; a nonlive vaccine may have greater acceptability to some potential vaccine recipients. Secondly, in contrast to MSP, which is not ubiquitous among all species of Legionella (25), membranes are a component of all Legionella. If $L$. pneumophila membranes induce cross-protective immunity against other species of Legionella, or if membranes of other Legionella species also induce protective immunity against the homologous species, then theoretically a membrane vaccine could be formulated that may protect against all species of Legionella that cause Legionnaires' disease.

\section{Acknowledgments}

We are grateful for Ms. Barbara Jane Dillon for expert technical assistance.

This work was supported by grant AI-22421 from the National Institutes of Health. Dr. Horwitz is Gordon MacDonald Scholar at the University of California, Los Angeles. During the time this work was performed, Dr. Blander was supported by National Institutes of Health training grant $\mathrm{AI}-07323$ and subsequently by a National Foundation for Infectious Diseases-Roerig Postdoctoral Fellowship in Nosocomial Infection Research.

\section{References}

1. Horwitz, M. A., and S. C. Silverstein. 1980. Legionnaires' disease bacterium (Legionella pneumophila) multiplies intracellularly in human monocytes. $J$. Clin. Invest. 66:441-450.

2. Wilkinson, H. W., A. L. Reingold, B. J. Brake, D. L. McGiboney, G. W. Gorman, and C. V. Broome. 1983. Reactivity of serum from patients with suspected legionellosis against 29 antigens of Legionellaceae and Legionella-like organisms by indirect immunofluorescence assay. J. Infect. Dis. 147:23-31.

3. Horwitz, M. A., and S. C. Silverstein. 1981. Interaction of the Legionnaires' disease bacterium (Legionella pneumophila) with human phagocytes. I. L. pneu- mophila resists killing by polymorphonuclear leukocytes, antibody, and complement. J. Exp. Med. 153:386-397.

4. Horwitz, M. A., and S. C. Silverstein. 1981. Interaction of the Legionnaires' disease bacterium Legionella pneumophila with human phagocytes. II. Antibody promotes binding of $L$. pneumophila to monocytes but does not inhibit intracellular multiplication. J. Exp. Med. 153:398-406.

5. Horwitz, M. A. 1983. Cell-mediated immunity in Legionnaires' disease. J. Clin. Invest. 71:1686-1697.

6. Horwitz, M. A., and S. C. Silverstein. 1981. Activated human monocytes inhibit the intracellular multiplication of Legionnaires' disease bacteria. J. Exp. Med. 154:1618-1635.

7. Nash, T. W., D. M. Libby, and M. A. Horwitz. 1984. Interaction between the Legionnaires' disease bacterium Legionella pneumophila and human alveolar macrophages: influence of antibody, lymphokines, and hydrocortisone. J. Clin. Invest. 74:771-782.

8. Bhardwaj, N., T. Nash, and M. A. Horwitz, Gamma interferon-activated human monocytes inhibit the intracellular multiplication of Legionella pneumophila. J. Immunol. 137:2662-2664.

9. Nash, T., D. M. Libby, and M. A. Horwitz. 1988. Gamma interferon activated human alveolar macrophages inhibit the intracellular multiplication of Legionella pneumophila. J. Immunol. 140:3978-3981.

10. Davis, G. S., W. C. Winn, Jr., D. W. Gump, J. E. Crayhead, and H. N. Beaty. 1982. Legionnaires' pneumonia after aerosol exposure in guinea pigs and rats. Am. Rev. Respir. Dis. 126:1050-1057.

11. Davis, G. S., W. C. Winn, Jr., D. W. Gump, and H. N. Beaty. 1983. The kinetics of early inflammatory events during experimental pneumonia due to Legionella pneumonia in guinea pigs. J. Infect. Dis. 148:823-835.

12. Baskerville, A., R. B. Fitzgeorge, M. Broster, P. Hambleton, and P. J. Dennis. 1981. Experimental transmission of Legionnaires' disease by exposure to aerosols of Legionella pneumophila. Lancet. ii:1389-1390.

13. Katz, S. M., and S. Hashemi. 1982. Electron microscopic examination of the inflammatory response to Legionella pneumophila in guinea pigs. Lab. Invest. 46:24-32.

14. Berendt, R. F., H. W. Young, R. G. Allen, and G. L. Knutsen. 1980. Dose response of guinea pigs experimentally infected with aerosols of Legionella pneumophila. J. Infect. Dis. 141:186-192.

15. Breiman, R. F., and M. A. Horwitz. 1987. Guinea pigs sublethally infected with aerosolized Legionella pneumophila develop humoral and cell-mediated immune responses and are protected against lethal aerosol challenge: a model for studying host defense against lung infections caused by intracellular pathogens. $J$. Exp. Med. 164:799-811.

16. Blander, S. J., R. F. Breiman, and M. A. Horwitz. 1989. A live avirulent mutant Legionella pneumophila vaccine induces protective immunity against lethal aerosol challenge. J. Clin. Invest. 83:810-815.

17. Blander, S. J., and M. A. Horwitz. 1989. Vaccination with the major secretory protein of Legionella pneumophila induces cell-mediated and protective immunity in a guinea pig model of Legionnaires' disease. J. Exp. Med. 169:691-705.

18. Blander, S. J., L. Szeto, H. A. Shuman, and M. A. Horwitz. 1990. An immunoprotective molecule, the major secretory protein of Legionella pneumophila, is not a virulence factor in a guinea pig model of Legionnaires' disease. $J$. Clin. Invest. 86:817-824.

19. Blander, S. J., and M. A. Horwitz. 1990. Cross-protective immunity to Legionnaires' disease induced by vaccination with the major secretory protein of Legionella. Clin. Res. 38:269A. (Abstr.)

20. Gabay, J. E., and M. A. Horwitz. 1985. Isolation and characterization of the cytoplasmic and outer membranes of the Legionnaires' disease bacterium Legionella pneumophila. J. Exp. Med. 161:409-422.

21. Laemmli, V. K. 1970. Cleavage of structural proteins during the assembly of the head of bacteriophage T4. Nature (Lond.). 227:680-685.

22. Towbin, H., T. Staehlin, and J. Gordon. 1979. Electrophoretic transfer of proteins from polyacrylamide gels to nitrocellulose sheets: procedure and some applications. Proc. Natl. Acad. Sci. USA. 76:4350-4354.

23. Johnston, K. H., and J. B. Zabriskie. 1986. Purification and partial characterization of the nephritis strain-associated protein from Streptococcus pyogenes, group A. J. Exp. Med. 163:697-712.

24. McMaster, P. R. B., V. C. W. Tsang, K. Wong, J. C. Feeley, and D. S. Gann. 1984. Comparative adjuvant activities of Legionella pneumophila and Mycobacterium tuberculosis. Int. Arch. Allergy Appl. Immun. 73:357-362.

25. Quinn, F. D., M. G. Keen, and L. S. Tompkins. 1989. Genetic, immunological, and cytotoxic comparisons of Legionella proteolytic activities. Infect. Immun. 57:2719-2725. 